\title{
Anatomical learning
}

\author{
D. N. Sinha \\ Formerly Professor \& HOD, Dept. of Anatomy, Government Medical College, Haldwani
}

Corresponding Author:

Email: drdnsinha@hotmail.com

\begin{abstract}
Learning Anatomy is more important for the understanding of Medical Science \& more for the contribution in basic research ${ }^{1}$. An individual history could give a status \& method which were prevalent during those day when computer was not available. Anatomical knowledge was greatly advanced \& extensive publication were made during those days.
\end{abstract}

Keywords: Anatomy, U.G., P.G. Training.

Received: $13^{\text {th }}$ December, 2017

Accepted: $05^{\text {th }}$ February, 2018

\section{Introduction}

My memoir is the history of the journey in the ocean of ANATOMY, where I tried to take out a drop of water. I could not do so, therefore I have decided to write all these in the form of script of my ANATOMICAL career right from undergraduate to the post graduate studies. This will be a humble tribute to the subject $\&$ the persons those who were creator to the path to facilitate the journey to a destination where I could understand little about the fabrics of this art of the ALMIGHTY.

\section{Undergraduate Study of Anatomy}

In 1964, I was selected for MBBS course at MLN Medical College, Allahabad. This college was affiliated to the University of Allahabad. It was the fourth batch and our Principal was Prof. Pritam Das MS, FRCS (England). He was excellent and true teacher of surgery and a parexcellent surgeon, who will be remembered years to come. Our classes have started on $8^{\text {th }}$ July, 1964. On the first day, I saw my Profesor\& Head of Anatomy, Prof. H.C. Verma, MBBS, MS(Luck), MS, Ph.D (Wisconsin) USA along with faculty members Dr. S.K. Saxena MS, Reader, Dr. O. N. Mehrotra, MS (Surg.) Lecturer and two important back bone teachers (Demostrators), Dr. S.M. Agarwal\& Dr. Muzammil Ullah. We have been formerly introduced to the respected teachers.

The classes in anatomy started on very first day. On the first day the Lecture was taken by Prof Verma and he taught us Anatomy of the skin. He was strict for the discipline and very punctual always engaged in his workings. We went to the dissection hall, the Cadavers were allotted to us. We paid due regards \& respect to the real teachers who sacrificed their lives for our learning of Anatomy. Cadavers are the soul learning material of Anatomy. Every student had been given single parts for the dissections. At that time there was no shortage of Cadavers \& the number was adequate being situated also at the place of sangam. We entered in Dissection hall with Cunningham's Dissectors \& Hamilton Text Book of Anatomy, dissecting Instruments Skin Marking Pencil, Inchtap, Practical Copy for making good diagrams as per the instructions, cloth for strapping the hands \& feet to avoid the dryness of the parts. All these were shown to the teachers to give proof that we were having all the material required during learning of anatomy. A large apron was needed to avoid the problems during dissection. The Anatomy department provided the beautiful wooden Bone Box containing all the bones of the body with printed paper pasted on box. As yet I did not see such an arrangement of bone supply in any medical college. The cadavers were nicely embalmed with formalin and other materials\& by the texture these were looked perfect for the dissection. As yet I did not see such a nicely embalmed bodies in any other places wherever I had worked as Professor \& Head of the Department. There was nice work culture \& workers were all disciplined \& followed the instructions of HOD \&nevertheless they were more responsible. In dissection hall, I had always noticed good \& cleaned towels \& soap cakes and antiseptic lotion for the cleaning the hand after the dissection by the medical students. The body procurement process was rightly planned \&drilled. There were petrol driven hares car, driver, attendant round the clock for the procurement of the dead bodies. An attendant was deputed to attend the phone calls for 
informations of the dead bodies. I have been told that there was good police cooperation \& the process of procurement was much facilitated by their help. The mortuary was well equipped with coolers body injection machine, electric saw \& automatic temperature timer etc., today I do not find such nice arrangement anywhere. Burial ground was well maintained with adequate place having date of buriel mentioned on a name plate \& showing the date when to dig it, everything was well documented. For the articulation of bones all the necessary equipments were made available. There were good bone collections, skeletons \& its remains plenty in numbers available in the department for the study of osteology. Osteology work was nicely managed by best possible articulating mechanism.

Museum was nicely organized with display of all models of embryologyand soft parts. Surprisingly, the soft parts depicting sectional Anatomy of the body were available even before the arrival of the concept of Anatomy for CT; MRI of the advanced technological equipment for the study of the human body. Soft parts were nicely dissected well coloured some of them were very helpful for our teaching material. Professor Verma had a large vision for the Anatomical study. Professor Verma did his Ph.D from wisconsin under the Professor Mossman, who was also a coauthor of the Human Embryology book. At that time it was one of the best book of Human Embryology. Today anatomists use it as a reference book like Gray's Anatomy. Teaching was followed as per the conventional line. Practical classes were based on regional Anatomy. Professor Verma used to teach Embryology, Dr. Saxena Gross Anatomy entirely based on the Gray's Anatomy. Dr. O.N. Mehrotra being earlier as a Surgeon, he taught us more applied Anatomy.Dr. S.M. Agarwal was simple teacher and used to teach us gross Anatomy very simplified manner \& Dr. MuzammilUllah used to deliver in depth \&always gave excellent diagrams of Anatomical structures.

During demonstration teachers used to follow the Cunningham's manual of practical Anatomy. That time the Cunningham's Book was used similar to the textbook of Anatomy. Cunningham Book was edited by the greatest Anatomist of that era. During those days Professor H.C. Verma used to circulate the comprehensive instructions sheets in different colours which used to have all information's about the routine working in the Anatomy e.g. how much dissection has to be performed, what diagrams to be made, what bones to be studied and examination dates etc. Emphasis \& importance of dissections areas, were also mentioned in the instructions. It was all most like encyclopedia of the Practical Learning of Anatomy. Now a days these instruction sheets are not seen anywhere in hitech development of learning of Anatomy. The instruction sheet was very explanatory \& with all possible informations. At that time students were not needed to ask anything in Practical classes, only instruction sheets\& Cunningham Books were enough to perform dissections. Instructions sheet also contained procedures to keep the dissection parts free from drying for further continuation of the dissection. We were not allowed to keep any part undissected. That time it was considered to be the disrespect to the cadavers. The idea was to acquire maximum knowledge from the cadavers $\&$ as this was considered to be the great teacher of the Anatomy. ${ }^{2}$

Since parts were individually assigned for the dissection as per schedule \& it was time bound, therefore all the students used to remain present \& were engaged working. At the end of every schedule, stages viva used to be held \& being taken by the respective demonstrators. Marks were allotted for dissections \&as well as for viva separately. Therefore, the dissection was more vital in those days and therefore students were never found irregular \& dissections were well attended. Some time we used to ignore our lunch time \& often performed dissections. I still feel that those days was golden time for the learning of Anatomy. At the end of schedule we had to appear in Part view, often conducted by Prof. Verma and Dr S.K. Saxena, Reader in Anatomy. In our time Dissection hall was in SRN Hospital which is now converted in the mortuary for Forensic department where post mortem is being done these days. Practical copy was needed to be completed with good diagrams of Anatomy as per the side of the dissections allotted. During those days if one had incidentally cut the nerves, tendon and vessels etc while performing the dissection, than it was to be shown in diagrams too by dotted line to depict discontinuity of the nerve or vessels. Therefore, it was essential to follow the dissecting stages line by line to learn the anatomy.

During part viva Professor Verma used to keep marks card to compare the progress \& performance of the students. Professor Verma used to visit Dissection Hall with prior notice to all of us. He used to see the dissections\& diagrams of the students. If spelling is wrong then one has to write ten times on the practical copy and that to be examined by the teachers. He was very strict in giving marks, even students 
those who got thirty percent marks remained happy \& used to celebrate. He was very good in setting the questions papers. The standard was excellent, when I compared with recent time. I could say that those were the real days of Anatomy Learning. One thing very important to tell, that at time when vacation was given than students had to appear in a test of Anatomy before leaving\& another test on the first day of return. This was clearly intend to tone up the teaching atmosphere without relaxation. Therefore, students remained active during vacation \& might have fully utilized the period for learning of the anatomy. Now we cannot see such type of interest in teaching activity so faithful to the students. This also shows the greatness of teachers who were totally committed to the teaching for the benefit of students. We were also taught about the radiological anatomy. We were also given sheets of the surfaces \& radiological Anatomy for the study. This was very useful because at that time no such good books were available for study. During my U.G. our examination of Anatomy was conducted by Prof. DNS Chaudhary. He was Ph.D in Anatomy from U.K. and he was Dean \& Principal of the Rewa Medical College. If I have to conclude, I shall be happy to describe that the period was totally dominated by the learning of Anatomy by the Cunningham's Manual of Anatomy. Dissection had been given due importance and our teachers took keen interest for extending the knowledge of Anatomy to the Medical students. I pay my tribute to all for their efforts to enhance and propagate the art of Anatomy. Prof. Verma will be remembered for ever for hard disciplined administrator in seeing the Anatomy to achieve its glory in Medical field. He was good research worker. He had several ICMR projects. When my reference of cancellous structure of Tarsal Bones was cited in Gray's Text Book of Anatomy, he congratulated me from the Nigeria. I have also availed an opportunity to publish few articles along with his co-authorship.

After the study of Anatomy, I could understand the meaning of Anatomy, derived from Greek (Ana - Up, Tome - cutting) and dissection (Latin), meaning (dis - asunder, secare - to cut). This indicated that without dissection; the fabrics of the human body could not be studied. Here Karma of Gita is depicted as Anatomy for the study of the medical sciences.

\section{Postgraduate study of Anatomy}

After sometime, the destiny again tracked me to the Anatomy for the postgraduate study. Although I was not interested to pursue, being inclined for the clinical subject. In 1970 I joined the department of Anatomy Institute of Medical Sciences BHU, Varanasi. When I joined it was college of Medical Science but after my joining I could see the change being named as an Institute of Medical Sciences. It was headed by Prof. K.N. Udupa M.S. FRCS as a Director of Institute. The Anatomy department was chaired by Prof. Shamer Singh M.S. FAMS, a noted Anatomist, who has contributed enough in research \& teaching. He did his post graduation under Prof. Inderjit Singh Diwan. Prof. Shamer Singh also visited USA \& obtained considerable experience in Teratology from Japan in association with Prof. Nishimura. During those days M.S. degree used to be tough and to obtain it in first attempt was further much difficult. Being trained in Teratology, he developed the department for the study of Experimental Embryology and its applied activities. Cyclophosphamide, anticancer drug was widely used in experimental animals for this work. I was the seventh P.G. student \& being in merit, my supervisor \& guide was Prof Shamer Singh. He gave me the Topic of Tissue Culture (organ culture). I was asked to do the Culture of Chick embryonic Limb bud in modified TROWEL organ culture method and also utilized Mitomycin - $\mathrm{c}$ for evaluation of its teratogenic effect. We have also modified the culture medium and even subsequently used Amniotic fluid of Chick embryos to find out suitable for the growth of explant. I had also done the chemical analysis of used media for DNA, RNA, glucose and lactic acid for assessment of the effect after the growth. Even Radioactive isotopes $\mathrm{S}^{35}$ was also used for the uptake study for the effect on Chondrogenesis in the implant. Microautography was also done besides histological study. Due to availability of good laboratory, I conducted my work in Surgical Research Laboratory at BHU. The laboratory was looked after by than Director Prof. K.N. Udupa \& Dr. G.C. Prasad. Ph.D Dr. G.C. Prasad was trained from Strangeway's Research laboratory Cambridge for tissue culture work. Dr. Prasad was very cordial \& did all possible help for my research work. Prof K.N. Udupa also used to visit laboratory very frequently and encouraged me maximum during research work. I pay my sincere tribute to them.

The PG. Teaching of BHU was of a high standard. Prof. Shamer Singh taught us Teratology, Dr. MM Mathur Comparative anatomy, Dr. A.P. Shukla, Electron microscopic structure of the tissue, Dr. A.K. Sanyal embryology, Dr. Sen Sharma, Genetics, Neuroanatomy, Dr. S.P. Singh Surgical Anatomy $\&$ incisions. P.G. Programme used to start from 
8 AM sharp for one hours regularly. All the teachers \& residents were mandatory to attend the P.G. activities. If anyone would come late or fails to attend he / she had to apply for one day casual leave. Post Graduate classes included. P.G. Lecture, Tutorials, Journal club seminars etc. After seminar, the residents were asked to submit script in the library for the departmental use. Teachers used to participate in Journal club. At that time important journals were available in the department library e.g. Journal of Anatomy (London) Acta Anatomica, Anat. Anz, teratology. Americal Journal of Anatomy, Anatomical Record, Journal of Embryology \& experimental Morphology. Comparative Neurology \& other various journals including Indian Journals of clinical interest.

Post graduates would have to attend all lectures, similarly every teachers were mandatory to attend including Professor \& head of Anatomy. There was no immunity for any one. After the lectures the teachers used to discuss what was wrong \& how to improve further. Residents were allotted demonstration classes for undergraduate classes and lectures too. Professor Shamer Singh was very firm for nicely running of the post graduate programme. He always encouraged us to present papers in national conference of Anatomical Society of India held at various places. I attended conferences during P.G. and presented papers. Department often used to celebrate if any paper being accepted or published. Department also used to bear the publication expenditures. All the experimental animals were made available at the department level. There was a very good animal house. Post graduates were not to pay anything even for the photographs etc. Professor used to remain happy on listening the good results in research \& publications. We often used to see smile in his faces. The first conference which I attended was held at Allahabad in December 1970 which was organized by Prof. H.C. Verma. The department had a very nice gross Anatomy museum, radiological museum, \& extensive display of models, soft parts of excellent nature $\&$ huge collection of the comparative anatomy material, including materials for history of Anatomy were also available.

After the registration for P.G. course, one had to go through a series of Lectures for general exposure of the research methodology, what we called as a common post Graduate classes, where we had been taught statistics, library, photography, biochemical equipment's, animal house, animal experimentation etc. It was a nice teaching programme. I do admire these events which were much useful for P.G. training ${ }^{3}$.
Postgraduate training was also directed to learn various others, like, embalming, preparation of Museum specimens, learning of various procedures for new histological staining. There was good collections of the embryological slides of chick embryo, rat embryos and pig which we were much useful for the embryological studies. As a Post graduate, we had given separate cadavers for dissection during training. We were asked to dissect all peripheral parasympathetic Ganglion, Celiac Ganglion, Stellate Ganglion \& all the postgraduate level dissection were asked to practice. I remember that I got celiac Ganglion with right crus of the diaphgram during M.S. Anatomy examination. We were also asked to take demonstrations of the Anatomy, as per the dissectors (Cunningham) and osteology. During those day Multiple Choice Questions were much prevalent. The first paper of Internal in U.G. examination used to be the question paper entirely from MCQ. We have learnt its framing $\&$ evaluation too. Even every time during part completion, P.G. were also examined by MCQ. PG had to appear in Terminal Examinations and marks used to be put on record and used to display on the Notice Board. Besides thesis work, we were also asked to conduct other research work. I have conducted the Teratological work in chick embryos. The article was published in Journal of Anatomical society of India \& even reference cited in US Literature in Teratology. We have also modified the technique of injection in chick embryos. During those days PG had to maintain a diary of keeping records of the embalming performed, special staining, Neuro histological staining, number of the Medical Education Programmes attended, special guest lecture \& every things used to be signed and verified by the respective teachers time to time. This record was needed for presentation in examination.

After the submission of thesis, a PG had to appear in Cognate Course examination in which the topics were, comparative anatomy, genetics $\&$ applied. This was required to be cleared as aprerequisite for the sent up for main University examination. The department was known for the Teratological research \& Neuroanatomy. That is why UGC sanctioned post of Professor in Teratology \& Neuro Anatomy. A large number of papers were published in International Journals from the departmental contribution. That time there was no shortage of the cadavers $\&$ adequate opportunity were given to post graduate to learn more anatomy by dissection of human cadavers. Due to availability of cadavers department of Anatomy published several papers on Gross Anatomy \& osteology. The 
infrastructure of the department was excellent Professor Shamer gave more emphasis on discipline and post graduate programme.

I was fortunate to obtain MS (Anatomy) in first attempt under the able guidance of Prof Shamer Singh. He was my internal examiner. My external examiner were Prof. P.N. Dubey (Nagpur) \& Prof A.C. Das (Lucknow), Professor P.N.Dubey was also a man of Tissue Culture (Organ Culture). He asked maximum about my research work \& even invited me to visit Nagpur to work with him during summer vacation Prof A.C. Das also asked me to join K.G's Medical College in 1973. There is special to mention about Prof Shamer Singh that being internal examiner \& he used to ask maximum Leading Questions as compared to the external examiners during M.S. Anatomy Examinations. He was well known for this gesture. He was also strict in giving calibrated marks. This was the unique feature of him during those days.

When I visited England in 1982, the training of BHU during MS (Anatomy), had helped me lot to get adequate exposure of advance training in Teratology Prof. Shamer Singh was very kind to post graduate and was always ready to help anyone who so ever asked him. He congratulated me when my work was cited in Gray's Text book of Anatomy regarding Cancellous Structure of Tarsal bones. I have honour of publishing papers in International \& Indian Journal with his coauthorship. It will be worth mentioning the names of the some of the books which were available for our study during our post graduate at IMS, BHU e.g. Gray's Anatomy, Cunningham's Practical Anatomy, Grant's Anatomy, Anatomy Book of Gardener, Grey, O'Rahilly, R.J. Last, Treves, Hollinshead Surgical Anatomy, Mc Greger, Frazer's Osteology, Tissues of the Body by Le Gros Clark. Human Embroyology by Hamilton Boyd and Mossman, Keith Embryology, Truex Carpenters, Neuroanatomy. Ranson Clark Neuroanatomy, Cunningham's Text Book of Anatomy, Ham's Histology and other books of Histological Techniques, Radiology, Surface Anatomy comparative anatomy \& Books of cytogenetics. We were also asked to read recent advances in Anatomy, Surgery, and Orthopaedics. We had been also posted in department of surgery, radiology and forensic department for learning the applied significance of Anatomy. We had to read several Journals regularly to see the articles related to the recent advances in Anatomy, where articles related to EM, TEM, SEM, Histochemistry, immunology, Neurohistochemistry often available for learning of the Anatomy at the post graduate level.

\section{Conclusion}

A great training programme is still desired in view of the changing scenario of Medical Science. We should not deviate from the original concept of the learning methods \& should not compromise in training programme. This will be fruitful for all to develop a good faculty \& infrastructure. Things may change but Anatomy will be same. This is in short a contribution for Medical Education.

\section{References}

1. Sinha D.N. (1986) Anatomy in its recent perspective IJME:25(2)1-3.

2. Sinha D.N. (2015) Ancient Human Cadaveric Dissection. National Journal of Clinical Anatomy. Vol (1),53-7.

3. Sinha D.N. (2016) Present Outlook of Anatomy in Medical Education. IJCAP, Vol 3 issue 3,2502. 